\title{
Da Miss-sambaqui ao monstro de Sobral \\ arqueologia paulistana entre os anos de 1930 e $1950 *$
}

\section{From Miss-Sambaqui to Sobral Monster archaeology in São Paulo between the 1930's and the 1950's}

\author{
RAFAEL DE ABREU E SOUZA** \\ Núcleo de Estudos e Pesquisas Ambientais \\ Universidade Estadual de Campinas \\ Campinas (SP) \\ Brasil
}

RESUMO O artigo tem como objetivo trazer novas perspectivas à história da Arqueologia brasileira no período de 1930 a 1950, a partir do exame de fontes diversas, como periódicos da grande São Paulo. Busca-se demostrar que a efervescência das pesquisas e do interesse pela arqueologia durante o período sofre duro golpe quando da institucionalização e profissionalização do campo, criando a dicotomia entre arqueólogos amadores e oficiais.

Palavra-chave arqueologia, São Paulo, instituições

ABSTRACT The article aims to highlight new data about the history of Archeology between the 1930s and the 1950s, through the examination of diverse sources, as the journals published in the Great São Paulo region. It intends to demonstrate that the research effervescence and the interest in Archeology during the period declined with the field institutionalization

\footnotetext{
* Artigo recebido em: 10/01/2013. Aprovado em: 04/07/2013.

** Contato: rafaelabsouza@yahoo.com.br.
} 
and professionalization, creating a dichotomy between official and amateur archaeologists.

Keywords archaeology, São Paulo, institutions

\section{Introdução}

Os anos de 1930 e de 1950 em São Paulo são de relativa efervescência para a Arqueologia brasileira. Efervescência no sentido de que é grande o número de referências, em periódicos, a cursos e grupos que se dedicam ao tema na época; relativa, pois todo esse boom sofrerá dura redução a partir dos anos 1960. Ganham forças problemáticas sobre o passado do planalto e do litoral paulista, no âmbito das preocupações sobre a antiguidade do homem americano; pós-1960, a Arqueologia sofre alguma estagnação, relacionada, para Pedro Funari, ${ }^{1}$ a repressão militar sobre o mundo acadêmico, até ser retomada, na região, enquanto Arqueologia Histórica já com os anos de 1980. Assiste-se, no período, a um incentivo à formação de comissões, missões, institutos e políticas de preservação para a região da grande São Paulo e municípios adjacentes. Intensifica-se o convite a especialistas estrangeiros que vêm colaborar com novas técnicas, métodos e classificações. ${ }^{2}$

A não identificação étnica e cultural com o passado indígena e o caráter não monumental do patrimônio material do nosso território dificultavam a valorização e a identificação cultural da sociedade com os vestígios arqueológicos; ${ }^{3}$ debates sobre progresso, modernidade e identidade nacional fortaleceram políticas culturais pautadas por projetos colonialistas que auxiliaram no extermínio de populações indígenas contemporâneas. ${ }^{4}$ Cresciam os embates sobre raça, origem e evolução; passado, civilizações perdidas e patrimônio. Grandes estrelas atuavam em filmes sobre Arqueologia: "Jacaré", "Serra Aventura", "Além do Saara", "Heróis de Homero", "A máscara de Ouro", "Segredo dos Incas", "Escravos do Amor das Amazonas", romanceavam o papel de arqueólogos e arqueólogas; a popularidade do tema era tanta que o Foto Cine Clube Bandeirante deu apoio à conferência sobre fotografia médica que apresentou debate sobre o uso do raio-X na Arqueologia, junto do Hospital das Clínicas, em 1957. Em 1959, na Folha da Manhã, a Arqueologia ganha destaque quando estudantes arqueólogos

1 FUNARI, Pedro P. A. A History of Archaeology in Brasil. In: MURRAY, Tim; EVANS, Christopher (ed.). Histories of Archaeology: a reader in the History of Archaeology. Oxford: Oxford University Press, 2008, p.328-430.

2 BARRETO, Cristina. A construção de um passado pré-colonial: uma breve história da Arqueologia no Brasil. Revista USP, São Paulo, n.44, p.32-51, dez./fev. 1999-2000.

3 BARRETO, Cristina. A construção de um passado pré-colonial.

4 FERREIRA, Lúcia M. Arqueologia do Sul do Brasil e Política Colonial em Hermann von Ihering. Anos 90, Porto Alegre, v.12, p.415-436, 2005. 
sequestram, na Sicília, o ator norte-americano Joseph Cotten e o obrigam a ter aulas de História e Arqueologia! Três anos antes, o periódico Nossa Voz publicava a triste notícia do ataque ao $12^{\circ}$ Congresso de Arqueologia de Jerusalém, quando um soldado jordaniano abriu fogo contra os delegados do Congresso em visita a escavações próximas ao kibutz de Ramat Rachel.

Paulo Duarte, Paul Rivet, Egon Shaden, Herbert Baldus, Frei Reginaldo de Sá, o casal Lévi-Strauss, o casal Emperaire, o casal Sievers, Nuto Sant'Anna, Ruy Tibiriçá, Waldemar Lefevre, Otorini de Fiori, José Anthero Pereira Jr., Loureiro Fernandes, Luís Saia, Ryuzo Torii, Paulo Shulz, Kiju Sakai, Eldino Brancante, Manuel Pereira de Godoy, Enzo Silveira e outros, representaram a presença e o trânsito de ideias de brasileiros, japoneses, italianos e franceses na construção, implementação e profissionalização da Arqueologia em São Paulo (e a partir de São Paulo), enquanto campo de conhecimento, e seu esforço na preservação de um patrimônio indígena pré-colonial, através de periódicos, publicações, cursos e reuniões. Os periódicos não faziam distinção, por não haver claramente, entre arqueólogos oficiais e amadores (Sakai era antropólogo formado no Japão e Paulo Duarte advogado pela Faculdade de Direito do Largo São Francisco, mas o primeiro, hoje, é classificado como "amador"). Em maio de 1953, a Folha da Manhã publica nota sobre o papel dos arqueólogos amadores norteamericanos e sua colaboração com os profissionais nas interpretações sobre a cultura Folsom. Como lembra André Prous, ${ }^{5}$ a conotação negativa da categoria "amador" no âmbito arqueológico é cara ao contexto brasileiro, não recorrendo em outros países, os quais tendem a incorporá-los a equipes e pesquisas.

A hipótese do relativo afastamento entre Arqueologia e imprensa, a partir dos anos 1960, ${ }^{6}$ parece estar relacionada a dois aspectos. Por um lado, ao processo de institucionalização e profissionalização da disciplina no país, que fortalecera a categoria dos arqueólogos "oficiais", aqueles ligados a instituições, deixando para os de fora a alcunha "negativa" de "amadores". Por outro, ao golpe militar e à instauração da ditadura cívicomilitar brasileira diretamente relacionados à fundação da maior parte das universidades e museus que concentraram os profissionais de arqueologia no período, ${ }^{7}$ concomitante ao fortalecimento da censura sobre os veículos de comunicação, como a imprensa, e, também por isso, a seu distanciamento de grupos intelectuais.

Até o final dos anos 1950 essa divisão fora pouco clara e os diálogos entre os diferentes pesquisadores em São Paulo foi bastante intenso. Nota-

\footnotetext{
PROUS, André. Arqueologia brasileira. Brasília: Editora da UNB, 1992.

TEGA, Gloria. Arqueologia no Brasil e o panorama atual: os números de 11 anos de divulgação na Folha de $\mathrm{S}$. Paulo. Arqueologia Pública, Campinas, n.5, p.14-27, 2012

7 FUNARI, Pedro P. A. A History of Archaeology in Brasil.
} 
se também, analisando os dados, que a Arqueologia em São Paulo não surgiu exclusivamente dentro das universidades, ${ }^{8}$ ocorrendo em diversos locais, seja a partir do Ministério da Agricultura, Instituto de Arqueólogos Paulistas, Escola de Sociologia e Política, Faculdade de Filosofia da Universidade de São Paulo, Sociedade Botânica Brasileira, Instituto de Pré-História e Etnologia, Museu de Arte Moderna, Museu Paulista, Associação Paulista de Medicina, Clube Zoológico Brasileiro, Comissão Geográfica e Geológica, Instituto Histórico e Geográfico de São Paulo, Centro Cultural Brasil-Suécia, Hospital das Clínicas, Instituto Oceanográfico da Universidade São Paulo, Centro Bíblico, Departamento Municipal de Cultura, Biblioteca Municipal, seja contando com pesquisas, cursos e conferências, em conjunto com o Museu do Homem de Paris, Universidade de Sophia de Tóquio, Universidade de Jerusalém etc. A Arqueologia ocorria em mais locais e possuía um escopo maior de atuação e assuntos do que posteriormente se assistiu, quando as instituições "públicas", como a Universidade de São Paulo, praticamente congregaram todos os reconhecidamente "oficiais" ou "profissionais".

A Lei 1.924 de 1961 representou grande avanço para a Arqueologia brasileira e paulista, resultado do envolvimento de Paulo Duarte, pelo Instituto de Pré-História (IPH), Castro Faria, do Museu Nacional, e Loureiro Fernandes, do Centro de Ensino e Pesquisas Arqueológicas da Universidade do Paraná. ${ }^{9}$ A criação do Museu de Arte e Arqueologia, tendo à frente Ulpiano Meneses, também representou um enorme avanço e fortalecimento da área a partir de 1963 (apesar das acusações, de Paulo Duarte, da iniciativa buscar destruir o IPH). ${ }^{10}$ Entretanto, tais iniciativas, para Alfredo Mendonça de Sousa, ${ }^{11}$ trouxeram um impulso cooperativista aos arqueólogos brasileiros, resultando na contraposição entre "profissionais" e "amadores", apesar da inexistência de uma formação universitária à época; o que definia um e outro passou a ser sua inserção em uma instituição "pública". Para Camila Wichers, ${ }^{12}$ deve-se lembrar que a importância dos "amadores" e de profissionais de áreas afins para a Arqueologia do território paulista foi enorme. Acompanharemos aspectos desse processo no presente artigo.

Os periódicos deixam claro também que a Arqueologia brasileira ganhava destaque nos meios midiáticos, concorria e suplantava imagens associadas a egípcios, romanos, dinossauros e megafauna. Apenas uma notícia reporta achados de um megatério, o mostro do Sobral, no Ceará, relacionando-o a estudos arqueológicos; por outro lado, o Departamento de

8 BARRETO, Cristina. A construção de um passado pré-colonial.

9 WICHERS, Camila A. M. Patrimônio Arqueológico Paulista: proposições e provocações museológicas. São Paulo: Universidade de São Paulo, 2012 (Arqueologia, Tese de doutorado).

10 HEYMANN, Luciana Q.; LACERDA, Aline L.; MENESES, Ulpiano B. Entrevista com Ulpiano Toledo Bezerra de Meneses. Estudos Históricos, Rio de Janeiro, v.24, n.48, p.405-431, 2011.

11 SOUSA, Alfredo M. História da arqueologia brasileira. Curitiba: 1991, Série Antropologia 46 (Pesquisas).

12 SOUSA, Alfredo M. História da arqueologia brasileira. 
Paleontologia em São Paulo realizava, à época, pesquisas em sambaquis, permitindo, assim, alguma associação com os paleontólogos.

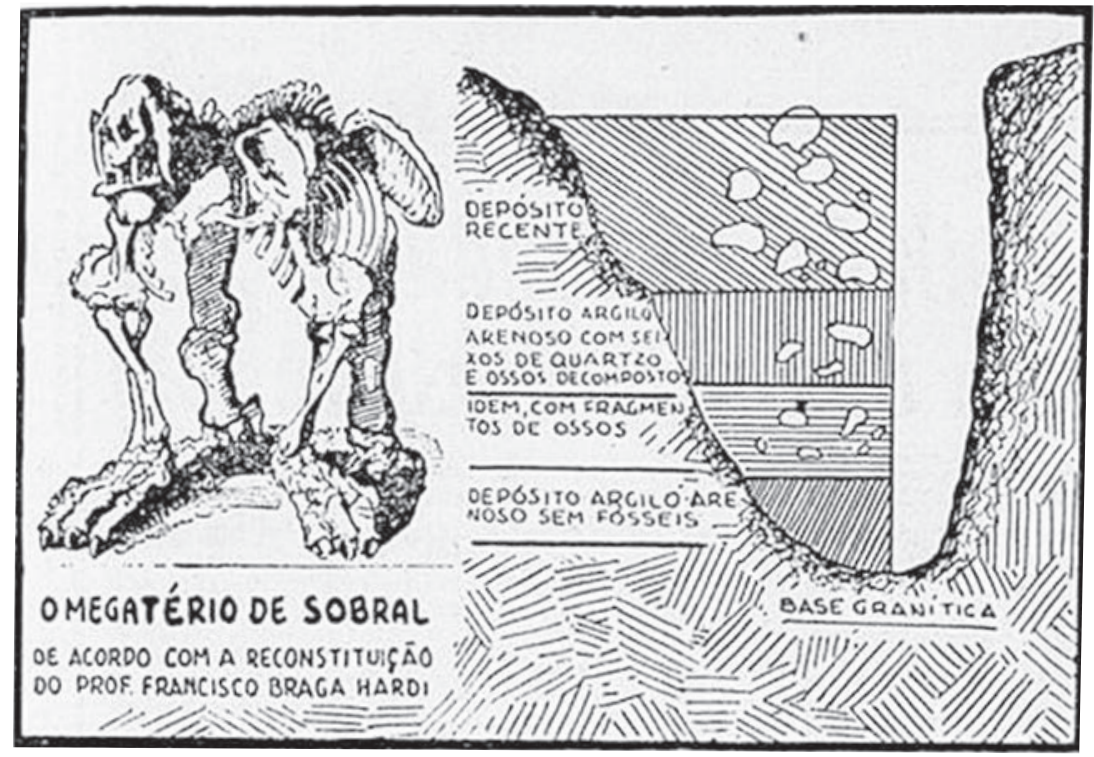

Monstro prehistórico que viveu a um milhão de anos descoberto

Figura 1. O megatério de Sobral. Jornal de Notícias, 25/03/1950.

Este artigo procura preencher algumas lacunas relacionadas à história da Arqueologia brasileira, em especial a paulista, nos anos 1930 e 1950, anteriormente, portanto, à Lei de 1961, utilizando fontes pouco frequentes para tal: os periódicos. Pressupõe-se que a rarefação nos estudos sobre a história da Arqueologia brasileira estaria relacionada à curta tradição de análises históricas e das ideias para as ciências humanas no Brasil em geral $^{13}$ (sem mencionar a ausência da Arqueologia Histórica nas sínteses sobre história da Arqueologia no Brasil). Optou-se por ressaltar algumas das redes que configuraram a Arqueologia no período de sua profissionalização, a partir de laços políticos que conectavam diferentes pesquisadores em relações cravadas por interesses e disputas de poder.

A escolha dos periódicos como fonte primária para este objetivo insere o artigo no campo de estudo da história (da arqueologia brasileira) através

13 FERREIRA, Lúcio M. Vestígios de civilização: o Instituto Histórico e Geográfico Brasileiro e a construção da Arqueologia Imperial (1838-1870). Revista de História Regional, Ponta Grossa, v.4, p.9-36, 1999. 
da imprensa, cuja periodicidade permite acompanhamento diário ${ }^{14}$ de determinados assuntos que podem ser trabalhados diacronicamente. A imprensa, no Brasil, conquista as ruas no início do século XX, a partir da venda avulsa, já que até o final do século anterior estava vinculada a postos fixos em livrarias e nas próprias redações. ${ }^{15}$ No século XIX, eram poucos os assinantes de periódicos fora do centro urbano, aspecto que muda a partir do século seguinte, com a ampliação do publico leitor e do público atingido pela divulgação de notícias e publicidades pela mídia impressa, dialógica a expansão da malha ferroviária, a chegada dos bondes, melhorias no correio e a venda dos jornais pelas ruas da cidade.

Por outro lado, a circulação dos jornais ainda estava restrita aos círculos letrados, a pequena burguesa urbana, com exceção de grandes notícias divulgadas por leituras públicas e conversas. Para grande parte dos historiadores, os anos de 1930 são considerados um período de consolidação da imprensa burguesa, afirmando um jornalismo informativo-utilitário a partir do final dos anos de 1920 devido aos episódios da Segunda Guerra Mundial. ${ }^{16}$ O período também é marcado pelo crescimento da importância da fotografia associada às notícias, o que tem suma importância nas reportagens sobre Arqueologia, ilustrando pessoas, objetos e lugares. Diferente da análise a partir da literatura arqueológica, a leitura dos periódicos permite a apreensão de perspectivas e discursos sobre a arqueologia a partir de fontes de natureza diversa, forjadas sobre crivos diferentes e circulantes em esferas outras.

Foram consultados, para além da literatura especializada, os periódicos Cine-Repórter (1946-1966), Correio de S. Paulo (1932-1937), Correio Paulistano (1930-1949), Diário Nacional (1927-1932), Diário Oficial de São Paulo (1930-1959), Flan (1953-1954), Folha da Manhã (1930-1959), Folha da Noite (1930-1959), Jornal de Notícias (1946-1951), Jornal do Estado (1930-1959), Nossa Voz (1947-1962) e O Governador (1950-1957), resultando em fonte de dados com 382 matérias, através dos arquivos da Hemeroteca Digital da Fundação Biblioteca Nacional e do Acervo Digital da Folha de S. Paulo. Os jornais foram selecionados a partir de sua própria disponibilidade nos centros de consulta.

\section{Prelúdio de igaçabas}

Em 1897, o general Couto de Magalhães sugeriu que o gosto pelo estudo das origens dos habitantes de São Paulo importava para compreender

14 ZICMAN, Renée B. Historia através da imprensa: algumas considerações metodológicas. Projeto História, São Paulo, v.4, p.89-102, 1985

15 JANOVITCH, Paula A. A mecanização da imprensa paulista através dos seminários paulistanos de narrativa irreverente (1900-1911). Revista de Historia, v.2, n.149, p.211-233, 2003.

16 ARAÚJO, Nelton S. Imprensa e poder nos anos 1930: uma análise historiográfica. Anais do VI. Congresso Nacional de História da Mídia, Niterói, 2008. 
como se formou a "raça paulista". Nesta toada, cresceram investigações sobre grupos indígenas passados e proliferaram registros de localizações de machados polidos e urnas funerárias. ${ }^{17}$ A classificação "igaçaba" passou a ser utilizada para referir-se aos grandes recipientes destinados a sepultamentos indígenas, evidências mais que concretas, junto de outras dimensões materiais em São Paulo, como as casas bandeiristas, de que os paulistas descendiam de uma "raça" forte, cujo ícone mor, o bandeirante, mesclava a bravura indígena e a civilidade europeia. Mostrava também que estes artefatos, associados a civilizações indígenas desaparecidas, poderiam compor a história da nação, vinculando-a a outras grandes civilizações ${ }^{18}$ já que representavam índios bravos e guerreiros, diferente daqueles ainda vivos (este é o momento das campanhas de extermínios dos Kaingang do Oeste Paulista). Von Ihering, interpretando os dados antropológicos e arqueológicos do Estado de São Paulo, conclui pela pobreza cultural dos "indígenas paulistas", sentenciando o extermínio dos Kaingang que resistiam ao avanço dos cafeicultores do oeste. ${ }^{19} \mathrm{O}$ índio histórico, "matriz da nacionalidade, tupi por excelência, extinto de preferência", antítese do índio contemporâneo, integrante das "hordas selvagens" que erravam pelos sertões, ${ }^{20}$ era materializado pelas antigas igaçabas.

O final do século XIX e o começo do XX foram marcados pelas viagens de naturalistas europeus que forneceram as primeiras descrições sistemáticas e específicas sobre ocupações indígenas. Assiste-se, neste momento, às primeiras escavações arqueológicas realizadas no Brasil, na Amazônia e nos sambaquis paulistas. ${ }^{21}$ Descrição, classificação e tipologia acompanhavam a Arqueologia lecionada e executada fora e dentro das faculdades.

Ao menos até os anos 1960, a Arqueologia encontrava-se em ebulição na grande São Paulo, dominada por uma "elite de especialistas", que debatia questões de raça e origem, ${ }^{22}$ ocorrendo em diversos núcleos, que não aqueles universitários, e que passaram, posteriormente, por um processo constante de "fechamento". Nas sociedades históricas e geográficas criadas durante a República, para além dos museus, a Arqueologia surgia de forma mais "popularizada", a exemplo das pesquisas sobre cidades perdidas, interpretações místicas de inscrições rupestres e presença fenícia. ${ }^{23} \mathrm{~A}$ Folha

17 ZANETTINI, Paulo. Maloqueiros e seus palácios de barro: o cotidiano doméstico da Casa Bandeirista. São Paulo: Universidade de São Paulo, 2005 (Arqueologia, Tese de doutorado); WICHERS, Camila A. M. Patrimônio Arqueológico Paulista.

18 SANJAD, Nelson."Ciência de potes quebrados": nação e região na arqueologia brasileira do século XIX. Anais do Museu Paulista, v.19, n.1, p.133-164, 2011

19 FERREIRA, Lúcio M. Arqueologia do Sul do Brasil e Política Colonial em Hermann von Ihering

20 LOURENÇO, Jaqueline. Visões sobre os povos indígenas durante o processo de independência do Brasil (18081831). São Paulo: Universidade de São Paulo, 2009 (História, Dissertação de mestrado).

21 ROBRAHN-GONZÁLEZ, Erika M. Arqueologia em perspectiva: 150 anos de prática e reflexão no estudo de nosso passado. Revista USP, São Paulo, n.44, p.10-31, dezembro/fevereiro 1999-2000.

22 BARRETO, Cristina. A construção de um passado pré-colonial.

23 BARRETO, Cristina. A construção de um passado pré-colonial. 
da Manhã, de agosto de 1958, atestava a passagem, por São Paulo, do arqueólogo francês Marcel F. Hamet e registrava suas pesquisas sobre a civilização do deus solar de Atlântida perdida na região do Araguaia. Em julho do mesmo ano, relatava a presença de pesquisadores do Museu do Brooklin, por 15 meses, na Amazônia, projeto anunciado pelo Diário Nacional de outubro de 1931, quando Desmond Holridge, também da mesma instituição, já "desbravava" a região.

Vale lembrar que este é um período com forte propensão à busca de vestígios considerados "nobres" do passado, devedor de visões coloniais de um colecionismo que foi ganhando novas formas com o surgimento do Museu Paulista ${ }^{24}$. Em São Paulo, predominaram os "achados fortuitos", seja de artefatos isolados coletados, seja compostos por coleções doadas provenientes de municípios como Mogi das Cruzes e São Paulo. ${ }^{25}$ Proliferaram levantamentos de dados primários, escavações e formulação de coleções dialógicas a hipóteses e teorias sobre a origem e filiação cultural dos índios brasileiros. A Arqueologia, junto da Antropologia Física, abria portas aos estudos culturais, com o difusionismo e o comparativismo cultural. ${ }^{26}$

Em 1885, foram localizados artefatos líticos e cerâmicos no antigo morro dos Lázaros, no bairro da Luz, e posteriormente, no começo do XX, diversas urnas associadas à tradição cerâmica tupi-guarani em diferentes pontos da cidade; ${ }^{27}$ Couto de Magalhães as associou aos Guianases..28 As obras realizadas em virtude da instalação de fábricas, linhas férreas e vilas operárias nas planícies fluviais dos rios Tietê, Pinheiros e Tamanduateí resultaram na localização de vestígios associados a antigas aldeias. A construção do prédio da Companhia Antarctica Paulista, na Mooca, em 1907, é um exemplo, quando operários encontraram um sepultamento em urna. ${ }^{29}$ Igaçabas com "restos de esqueletos" constam nos bairros do Brás (1896), Mooca (1907 e anos 1950), Penha (1920), Pari (sem data), Brooklin (1960), Vila Maria (1960) e em Guarulhos (1959). ${ }^{30}$ Conta-se, ainda, para os anos de 1960, com o trabalho de Pereira Jr. sobre a cerâmica indígena do bairro do Morumbi. ${ }^{31}$

A recorrência das igaçabas, nos periódicos e em outros veículos de circulação escritos, e as interpretações tecidas sobre as mesmas, indicam

24 WICHERS, Camila A. M. Patrimônio Arqueológico Paulista.

25 WICHERS, Camila A. M. Patrimônio Arqueológico Paulista.

26 BARRETO, Cristina. A construção de um passado pré-colonial.

27 ZANETTINI, Paulo. Maloqueiros e seus palácios de barro.

28 COUTO DE MAGALHÃES, José V. $7^{a}$ Conferência para o Tricentenário de Anchieta. Assumpto: Anchieta, as raças e línguas indígenas. São Paulo: Typographia Carlos Gerke e Cia., 1897.

29 WICHERS, Camila A. M. Patrimônio Arqueológico Paulista.

30 PEREIRA JR., José A. Em torno das pesquisas arqueológicas realizadas no sítio da antiga igreja dos jesuítas no 'Pátio do Colégio', no ano de 1973. Revista do Arquivo Municipal de São Paulo, ano 38, v.187, 1975; ZANETTINI, Paulo. Maloqueiros e seus palácios de barro; SANT'ANNA, Nuto. São Paulo histórico (aspectos, lendas e costumes), v.5. São Paulo: Departamento de Cultura, 1944

31 PEREIRA JR., José A. Cerâmica indígena do bairro do Morumbi (primeiras informações). Apontamentos Arqueológicos, São Paulo, n.6, p.1-6, 1964. 
que os vestígios arqueológicos eram vistos como hipotéticos signos de civilização, índices que comporiam a identidade nacional com sua porção indígena. ${ }^{32}$ Auxiliando na delimitação de fronteiras nacionais, da modernidade paulista surgiram leituras arqueológicas que fortaleceram políticas coloniais ao hierarquizar o índio morto (e o vivo) em graus de civilização. ${ }^{33}$ Com frequência chegavam aos leitores paulistas notícias sobre igaçabas encontradas em Pirassununga, Piracicaba, Taubaté, São Paulo, Praia Grande, relacionadas à "morte heroica", à "religiosidade" e à arte de uma civilização um dia louvável.

Crescente interesse pela Arqueologia abre, portanto, os anos de 1930. Pesquisadores organizavam-se ao redor de diversas instituições para buscar o antigo sepultado sobre a cidade moderna de concreto que se erguia no planalto e espalhava seus tentáculos ao litoral e ao interior. Diversos jornais, desde aqueles das comunidades imigrantes até os grandes periódicos de circulação nacional, traziam notícias e matérias em que a Arqueologia, se não era o foco, ganhava destaque. Com o fortalecimento de algumas instituições, no entanto, regimes de verdade foram favorecidos, também por posições políticas de destaque (como a do próprio Paulo Duarte). E a partir dos anos de 1960 parece assistir-se a um relativo recrudescimento do campo, acompanhado de sua institucionalização e da profissionalização dos arqueólogos, transformando aqueles que ficaram de fora das instituições (do poder, para lembrar Foucault) em "amadores" e, portanto, com uma produção que não merecia crédito no novo campo que se consolidava.

\section{Os anos de 1930}

Apesar de pesquisas arqueológicas e núcleos de Arqueologia estarem se formando na cidade de São Paulo, são poucas as intervenções arqueológicas propriamente feitas em âmbito regional. Pesquisas organizam-se em torno de missões francesas e japonesas, mas há outros atuando. Notas sobre o falecimento de "grandes" arqueólogos são frequentes, assim como ganham destaque pesquisas de arqueólogos italianos e alemães (o que permite questionamentos sobre a influência da aproximação entre o Brasil e o Eixo).

Um grupo de pesquisadores realiza estudos arqueológicos a partir da Sociedade de Ethnografia e Folclore (1937-1941) tendo à frente Mario de Andrade, então diretor do Departamento de Cultura de São Paulo, contando com a presença do casal Lévi-Strauss e de Ruy Tibiriçá. O dentista Ruy

32 NOELLI, Francisco; FERREIRA, Lúcia M. A persistência da teoria da degeneração e do colonialismo nos fundamentos da Arqueologia Brasileira. História, Ciências, Saúde-Manguinhos, v.14, n.4, p.1239-1264, 2007.

33 FERREIRA, Lúcio M. Gonçalves Dias: arqueólogo e etnógrafo. In: LOPES, Marcos Antônio (org.). Grandes nomes da história intelectual. São Paulo: Contexto, 2003, p.456-464. 
Tibiriçá, catedrático de farmácia, odontologia e obstetrícia da Universidade de São Paulo, em 1935, nas sessões mensais do Clube Zoológico Paulista, ministrou palestras sobre "cerâmica prehistorica paulista", "cerâmica amazônica", "inscripções lapidares" e "archaeologia brasileira". Utilizou a Revista do Arquivo Municipal, um grande veículo para publicação de estudos arqueológicos, a fim de apresentar suas teorias sobre a relação entre os gregos e a cultura marajoara. ${ }^{34} \mathrm{O}$ interesse pela cerâmica o levou a refletir sobre processos de hibridismo cultural em torno do que classifica como "cerâmica cabocla", escavando um sítio histórico em São José dos Campos e propondo uma primeira interpretação para as cerâmicas de produção local/regional, muito antes do estabelecimento da "tradição neobrasileira" pelo Programa Nacional de Pesquisas Arqueológicas (PRONAPA).

Entre 1935 e 1936, Tibiriçá publica estudos sobre a cerâmica de Cachoeira de Emas, em Pirassununga, a partir de peças coletadas por sondagens arqueológicas realizadas por Dina Dreyfus e Claude Lévi-Strauss; vale lembrar que algumas das peças vão para o Museu de Entografia da Faculdade de Filosofia da Universidade de São Paulo (USP), através de Plínio Ayrosa. Há notícias de que o próprio Mário de Andrade teria coletado urnas pelo interior do estado; Lévi-Strauss toca na Arqueologia como pauta das disciplinas ministradas em São Paulo. ${ }^{35}$

Também nos anos de 1930, a preocupação com a busca de uma identidade nacional associada ao paulista e a construção do mito bandeirante acarretam importantes movimentos relacionados à atuação de Mário de Andrade junto ao antigo Departamento de Cultura e sua associação a Rodrigo Mello Franco, o que resultou no início da política de tombamento das "casas bandeiristas" de taipa de pilão da região, preservando, no meio urbano, porções de terreno que viriam a ser escavadas nos anos 1940 e mais tarde nos anos 1980.

Entre 1935 e 1939 outros cursos de Arqueologia foram ministrados na cidade: em 1935, Annibal Mattos, pelo Instituo Histórico e Geográfico de São Paulo, ministra curso sobre Pré-história e o papel de Peter Lund em Lagoa Santa; em 1937, Franklin Moura, pela Associação Paulista de Medicina, conferencia sobre a "Alimentação na Pré-história", enquanto a missão nipo-brasileira traz à cidade Ryuzo Torii e seu filho Ryujiro Torii, arqueólogos da Universidade de Sophia, Tóquio. Os Torii ministrariam cursos sobre pré e proto-história japonesa, na USP, trocando experiências com a Sociedade de Ethnographia e Folclore ao estudarem os sambaquis do Iguape, além de visitarem o Museu Emílio Goeldi, no Pará; em 1939, Otorini di Fiori Caproni fala sobre a "Pré-História Paulistana" também na Universidade de São Paulo.

34 WICHERS, Camila A. M. Patrimônio Arqueológico Paulista.

35 WICHERS, Camila A. M. Patrimônio Arqueológico Paulista. 


\section{Viajando em missão cultural}

A CHEGADA, HONTEM, A S. PAULO, DO ARCHEOLOGO JAPONZ DR. RYUZ0 TORII

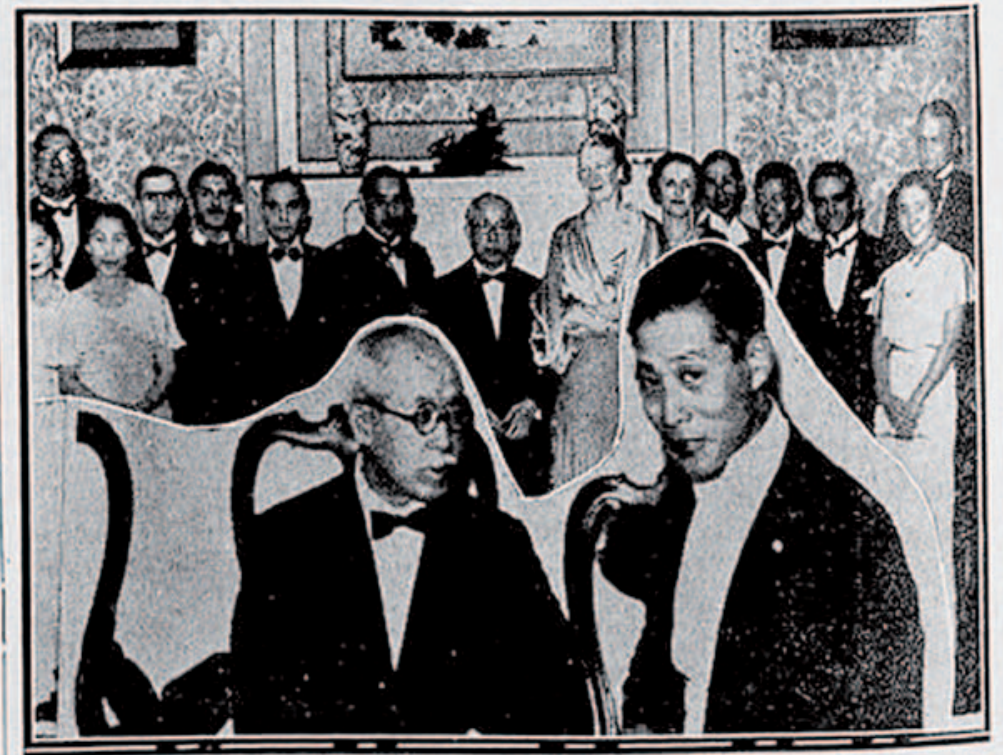

Aepectos da rocopçăo do hontom, vendo-zo um aspecto das pessoas presentes, o o distincto scies: tiata japonoz om companhla do consul st. Kozo Itigó

Figura 2. A chegada do arqueólogo Ryuzo Torii em São Paulo. Correio Paulistano, 12/05/1937, p.1

A Sociedade Arqueológica Brasileira de Amadores (SABA), fundada em 1936 por imigrantes japoneses em conjunto com arqueólogos formados no Japão, escava sambaquis no Vale do Ribeira (como o Alecrim, em Pedro de Toledo) e inaugura pesquisas arqueológicas associadas ao período colonial nos montículos funerários Kaingang dos municípios de Lins, Promissão e Guararapes. A SABA atuava no interior do Instituto de Pesquisas de Ciências Naturais Kurihara, fundado no início dos anos 1930 na Colônia Japonesa $1^{\text {a }}$ Aliança, em Mirandópolis, e transferido para a cidade de São Paulo em 1935. ${ }^{36}$

Vale ressaltar que a "missão japonesa" no estado de São Paulo ganha destaque com o papel do antropólogo Kiju Sakai, a partir de 1937. Com ele, fortalece-se o Instituto Kurihara que editava a revista Natura, na qual

36 WICHERS, Camila A. M. Patrimônio Arqueológico Paulista. 
constam trabalhos de arqueologia no estado. A missão japonesa para a arqueologia no Brasil, certamente fortalecida pela imigração, contou com a participação dos Torii e de Goro Hashimoto. Sakai e muitos outros, no entanto, voltaram ao Japão com a Segunda Guerra Mundial e retornam ao Brasil décadas mais tarde.

Um ano antes, em outubro de 1936, o Correio Paulistano publica matéria sobre a Comissão Pró-Missão Salesiana de Cathechese do Gentio Brasileiro, que apoia e realiza campanhas arqueológicas no Alto Rio Negro e chama atenção para a importância do sambaqui do Casqueiro, em Santos. A Missão Salesiana conta com o esforço de Plínio Ayrosa e da fundação do Museu Ethographico de São Paulo para que os paulistas destaquemse em educar os irmãos brasileiros na proteção do passado indígena. A matéria indica, ainda, que em 1900 a Missão Salesiana havia fundado, na Sé, a Associação de Ethnographia e Civilizações dos Índios, que durou dois anos, com o mesmo intuito.

Sem dúvida, os sambaquis ganham cada vez mais destaque. Alfredo Mendonça de Sousa ${ }^{37}$ mapeia, para a época, os estudos, em sambaquis, de Lebzelter (1933), Paulino de Almeida (1935) e Otorini di Fiori (1939), focados, em especial, na baixada Santista e Iguape. Nos anos 1930, Paulo Duarte passa a utilizar os veículos de comunicação, enquanto jornalista, para dar início ao embate em torno da proteção dos sambaquis e do patrimônio cultural como um todo. Em 1937, o Diário Oficial de São Paulo publica seu texto "Contra o vandalismo e o extermínio". No mesmo ano, Herbert Baldus passa a compor o Departamento de Antropologia da Fundação Escola de Sociologia e Política de São Paulo (FESPSP) onde leciona a disciplina de Etnologia do Brasil Meridional. Em torno dele, tem início pesquisas arqueológicas na FESPSP e a fundação da Revista de Sociologia que publica, entre 1930 e 1960, diversos artigos de Arqueologia.

O exame dos periódicos mostrou que 38 foram as matérias de divulgação científica sobre Arqueologia, 19 ofertas de publicações (a maioria da Revista do Arquivo Municipal, mas alguns livros de Arqueologia brasileira), 4 sobre patrimônio (sendo um texto-denúncia de Paulo Duarte) e cinco notas sobre a visita dos Torii. No que concerne aos assuntos, predominam a Arqueologia Brasileira, com 12 matérias (sendo 5 sobre sambaquis e 1 de Arqueologia Amazônica), 10 de Arqueologia pré-colombiana, 9 de Arqueologia Clássica, 2 de Arqueologia no Japão, 3 de Arqueologia do Egito, 1 de Arqueologia do Irã, 1 de Arqueologia do Saara e 1 de Arqueologia na Tchecoslováquia.

No total, 43 pesquisadores e 22 instituições são apresentados ao público leitor (Quadro 1):

37 SOUSA, Alfredo M. História da arqueologia brasileira. 


\section{Quadro 1}

Pesquisadores citados nos periódicos nos anos 1930

\begin{tabular}{|c|c|c|}
\hline Angione Costa & Enzo Silveira & Juan Fernandez Lopez \\
\hline Annibal Mattos & Franklin de Moura Campos & Byron Khun de Prorok \\
\hline Desmond Holridge & Jorge Bahlins & Plinio Ayrosa \\
\hline Major Bernard de Pontole & Paulo Duarte & Chakib Arsian \\
\hline Otorini de Fiori & Raymundo Moraes & André de Rezende \\
\hline Ruy Tibirićá & Ryuzo Torii & Sylvanus G. Mortey \\
\hline Ryujiro Torii & Bernardo Ramos & Kuhlmann \\
\hline H. Brown & Edmond Potter & Walter Andrae \\
\hline Senador Darchiani & George Walter & Ugo Holscher \\
\hline Frederico Halbherr & G. Roeder & George E. Duncan \\
\hline Alberto Escalona & George Livington Robinson & Prof. Morris \\
\hline Arthur Evans & Emil Ludwig & Richard Halliburtun \\
\hline Antonio Ferrano & Karl Absolon & Gustavo Mattos de Siqueira \\
\hline Eduardo Gerhard & Julio C. Tello & Della Corte \\
\hline Williams Thones & & \\
\hline & & \\
\hline
\end{tabular}

Predominam as citações sobre Ruy Tibiriçá, devido a suas conferências e publicações (16 vezes), seguidas pelas notícias da chegada e do itinerário de Ruyzo Torii (6 vezes). Das instituições, sete delas eram sediadas em São Paulo (Quadro 2):

Quadro 2

Instituições citadas nos periódicos nos anos 1930

\begin{tabular}{|l|l|}
\hline Academia Riograndense de Letras & Universidade de Catania \\
\hline Associação Paulista de Medicina & Universidade de Roma \\
\hline Clube Zoológico do Brasil & Universidade de Sophia \\
\hline Instituto Histórico e Geográfico de Santos & Universidade de São Paulo \\
\hline Instituto Carnegie (EUA) & Museu Archaeologico e Ethnographico \\
\hline Instituto Archaeologico Allemão & Academia Portuguesa de Historia \\
\hline Museu Emilio Goeldi & Faculdade de Direito/USP \\
\hline Museu Norte-Americano de Historia & Instituto Oriental da Universidade de \\
\hline Museu Pellzans de Hildesheim (Alemanha) & Associação de Inscripçoes e Bellas Letras \\
\hline Congresso de Homens de Sciencia & França \\
\hline Portugal) & Academia dos Lynces (França) \\
\hline Museu Etnhográphico de São Paulo & Faculdade de Medicina/USP \\
\hline
\end{tabular}




\section{Os anos de 1940}

O Correio Paulistano, em julho de 1941, publica matéria sobre a intelligentsia brasileira e como esta tinha se voltado "para as coisas do país"; a Arqueologia é elencada como uma das áreas com maior ânsia de conhecer o Brasil. Os jornais anunciam publicações e os filmes com mote arqueológico espalham-se pelos cinemas da Pauliceia. Em 1942, o filme "Jacaré" era rodado na Amazônia.

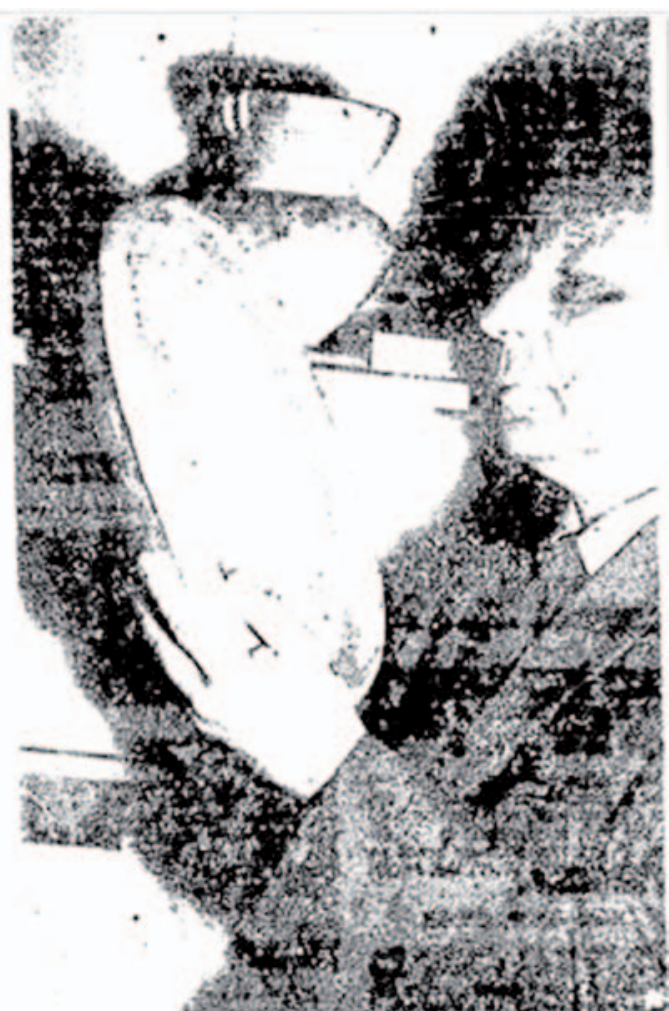

O prof. Baldus mostra uma gamela de barro dos índios tupinambás

Figura 3. Herbet Baldus segura uma gamela tupinambá. Folha da Manhã, 15/03/1953.

O entrar dos anos de 1940 assiste ainda a algumas publicações de Ruy Tibirçá, como "O Homem do Sambaqui", e as pesquisas de Otorini de Fiori sobre paleoetnografia em sambaquis, pelo Departamento de Geologia e Paleontologia da Faculdade de Filosofia da USP. Escavações em sambaquis de Santos são realizadas ao longo de toda a década. Em 1942, L. Hippolito e S. Schultz, da Sociedade de Biologia do Brasil, na $1^{\text {a }}$ Reunião Conjunta da Sociedade de Biologia do Brasil ocorrida em Paranapiacaba, 
apresentam os resultados dos trabalhos na Ilha de Santo Amaro. Herbert Baldus continua a ministrar cursos pela FESPSP, na qual, entre 1943 e 1946, faz o bacharelado Fernando Altenfelder Silva, que nos anos 1950 levaria a cabo estudos em sítios arqueológicos da região de Rio Claro, interior do estado. ${ }^{38} \mathrm{Em}$ 1947, ocorrem escavações no Guarujá e em três sambaquis da llha de Santo Amaro, sob a coordenação de Baldus, pelo departamento de Antropologia da FESPSP, contando com a presença do Dr. Hoge, do Instituto Butantã, e dos biólogos Girgio Schreiber e Ettore Biocca, a realizar o que denominaram de "Arqueologia Biológica". O biólogo italiano Ettore Biocca, em 1941, publica estudo sobre sambaquis e denuncia as destruições sofridas pelo famoso sambaqui do Mar Casado. ${ }^{39}$

Entre 1941 e 1949, são oferecidos alguns cursos na cidade: em dezembro de 1941, Ramayana Chavalier ministra curso sobre Arqueologia Amazônica; em setembro de 1946, o professor da Universidade de Jerusalém, Frederico Laschamnn, apresenta detalhes da arqueologia na Turquia, na Universidade de São Paulo, e sobre Arqueologia no Egito, na Escola Caetano de Campos, na Praça da República; em 1947, chega à cidade o arqueólogo da Universidade de Harvard John Kenneth Conant, que ministra curso sobre "Arqueologia Mundial" no Instituto de Engenharia. Em 1948, a Escola Universitária de São Paulo, no colégio Presidente Roosevelt, na Liberdade, oferece curso de museus com disciplina sobre Arqueologia Brasileira; no mesmo ano, Bruno Ghett ministra, na USP, conferência sobre as escavações na Basílica de São Pedro, no Vaticano. No final da década, a USP e a Universidade de Barcelona oferecem cursos de verão na Espanha sobre Arqueologia Pré-histórica e Clássica.

Em 1940, a Arqueologia da região metropolitana vê escavada a primeira casa bandeirista (no escopo do que seria chamado de Arqueologia Histórica a partir dos anos de 1960), o sítio Santo Antônio, em São Roque, por Loureiro Fernandes a convite de Luís Saia, então diretor do Serviço do Patrimônio Histórico e Artístico Nacional (SPHAN), a fim de realizar prospecções durante a restauração da casa. Fernandes já havia tido contato com o restauro, quando Rodrigo Mello Franco assume as obras do antigo colégio dos Jesuítas que sediaria o Museu de Paranaguá; Franco e Saia trabalharam juntos por alguns anos. Os trabalhos no sítio Santo Antônio, a partir de 1945, representaram ações de vanguarda no campo da Arqueologia e do Restauro. ${ }^{40}$ Em fevereiro de 1941, o Correio Paulistano indica que "serão feitas pesquisas no subsolo do Patio do Colegio", concernente aos estudos a serem desenvolvidos devido às obras da Secretaria de Viação e Obras Públicas, ressaltando a possibilidade de localizar enterramentos humanos (e ouro).

38 SILVA, Fernando Altenfelder. Informes preliminares sobre a arqueologia de Rio Claro. Programa Nacional de Pesquisas Arqueológicas, resultados preliminares do primeiro ano 1965-1966, Belém, n.6, p.79-88, 1967.

39 SOUSA, Alfredo M. História da arqueologia brasileira.

40 GONÇALVES, Cristiane S. Restauração arquitetônica: a experiência do SPHAN em São Paulo, 1937-1975. São Paulo: Annablume, Fapesp, 2007. 
A preocupação com a Arqueologia enquanto patrimônio expande o campo de atuação. A prefeitura abre vaga para delegado de Polícia, tendo como uma de suas atribuições organizar inquéritos em torno de dano à coisa de valor artístico, arqueológico ou histórico, segundo o art. 165. Em 1948, a Câmara Municipal discute os caminhos do crescimento urbano e o deputado Dumon Villares põe-se a frente de uma política de planejamento que englobe estudos e amplas pesquisas sobre história, arqueologia e arquitetura nas cidades, em prerrogativa bastante precoce para o campo da Arqueologia Urbana em São Paulo. A Arqueologia deveria ser considerada para que os objetivos dos urbanistas de elaborar um plano de remodelação da cidade (aumentando espaços livres no centro, tornado os alojamentos da população mais satisfatórios, resolvendo problemas com gastos de locomoção e abrindo oportunidades de recreação) fossem atingidos. ${ }^{41}$

A questão da proteção dos sambaquis ganha força. O Decreto $\mathrm{n}$. 7.468, de 31 de Julho de 1947, constitui uma comissão para proteção dos sambaquis do estado de São Paulo, a partir do Instituto Geológico e Geográfico do Estado de São Paulo e do Ministério da Agricultura, contando com a Diretoria Regional de Geografia, a Faculdade de Filosofia, Ciências e Letras, o Museu Paulista, o Departamento de Zoologia e a Procuradoria do Patrimônio Imobiliário. A partir de então, membros envolvidos na Comissão, como Herbert Baldus, Waldemar Lefevre e Bueno de Azevedo Filho, passam a frequentar os órgãos do legislativo a pregar o tombamento e a proteção dos sambaquis, com apoio de deputados como José Romeno Ferreira e Juliano Alvim. Vale ressaltar ainda que Sérgio Buarque de Holanda, em 1946, assume a direção do Museu Paulista, contratando Herbert Baldus e Harald Schultz, que desenvolveriam estudos arqueológicos e incrementariam a Arqueologia no Museu neste momento. ${ }^{42}$

Desde o final dos anos 1930, o jornalista Nuto Sant'Anna ganhava destaque com pesquisas sobre a cidade de São Paulo. Esteve a frente do Correio Paulistano durante os anos 1910 e funda a Revista do Arquivo Municipal nos anos 1930. Fora membro do Instituto Geográfico e Histórico de São Paulo, da Academia Paulista de Letras e da Seção de Documentação Histórica do Departamento de Cultura da Prefeitura Municipal de São Paulo. Entre 1937 e 1944, publica os diversos volumes de São Paulo histórico, com capítulo sobre as "Igaçabas" e suas localizações (Luz, Pari, Mooca etc.).

Os periódicos pesquisados trazem ao público livros, cursos e divulgam a atuação de 55 envolvidos com Arqueologia. É dada a chance, ao público letrado ao menos, e a oportunidade, de conhecer questões arqueológicas e arqueólogos de todo o mundo, do Brasil inclusive.

41 Diário Oficial de São Paulo, 02 jun. 1948, p.23.

42 WICHERS, Camila A. M. Patrimônio Arqueológico Paulista. 
Quadro 3

Pesquisadores citados nos periódicos nos anos 1940

\begin{tabular}{|c|c|c|c|}
\hline Otorini de Fiori & Carlos Rubena & $\begin{array}{c}\text { Guilherme de } \\
\text { Almeida }\end{array}$ & $\begin{array}{c}\text { Frederico } \\
\text { Laschmann }\end{array}$ \\
\hline Ruy Tibiriçá & Antonio Serrano & Angyone Costa & Herbert Baldus \\
\hline Amedeo Maiuri & Ramayana Chavalier & Afonso do Paço & Dr. Hoge \\
\hline H. G. Wells & Prof. Hackin & Machado Faria & Girgio Schreiber \\
\hline Julian Huxley & João Batista de Rosi & A. Almeida Prado & Ettore Biocca \\
\hline G. F. Wells & Annibal Mattos & Paulo Duarte & Henrique Rihetti \\
\hline Bueno de Azevedo & Barbosa Rodrigues & José Pereira Jr. & John Kenneth \\
Filho & Conant \\
\hline Georgius Fabricius & Hermann Von Hering & Gastão Bittencourt & Léo Pulcher \\
\hline Boucher de Perthes & L. Hippolito & Prosper Mérimée & Victor Segnien \\
\hline Roger Ambrusier & S. Schultz & Eugenio Jalhay & Roberto Paktos \\
\hdashline Bruno Ghett & Waldemar Lefevre & Maurice Ewing & Jean Marais \\
\hline Luis Saia & Peter Lund & Jean Cocteau & Kiju Sakai \\
\hline $\begin{array}{c}\text { Godofredo von } \\
\text { Loschan Solstein }\end{array}$ & $\begin{array}{r}\text { Trudo von Loschan } \\
\text { Solstein }\end{array}$ & Naji Al Alseel & Wilhem Doerpfeld \\
\hline Kuhlmann & Ryuzo Torii & Axel Perssen & \\
\hline
\end{tabular}

Aumenta o número de instituições envolvidas com Arqueologia citadas nos periódicos, de 22 para 34. Destas, 19 tinham sede na cidade de São Paulo e uma no interior do estado (Piracicaba) (Quadro 4).

\section{Quadro 4}

Instituições citadas nos periódicos nos anos 1940

\begin{tabular}{|c|c|c|}
\hline $\begin{array}{c}\text { Departamento de Geologia } \\
\text { e Paleontologia, Faculdade } \\
\text { de Filosofia da USP }\end{array}$ & $\begin{array}{c}\text { Diretoria Regional de } \\
\text { Geografia }\end{array}$ & Instituto Kurihara \\
\hline $\begin{array}{c}\text { Instituto Histórico e geográ- } \\
\text { fico de São Paulo }\end{array}$ & Museu Paulista & $\begin{array}{c}\text { Serviço de Arqueologia do } \\
\text { Iraque }\end{array}$ \\
\hline $\begin{array}{c}\text { Colégio de Meissen } \\
\text { (Inglaterra) }\end{array}$ & Departamento de Zoologia & $\begin{array}{c}\text { Museu Greco Romano de } \\
\text { Alexandria }\end{array}$ \\
\hline $\begin{array}{c}\text { Sociedade de Arqueologia } \\
\text { de Lorena (França) }\end{array}$ & $\begin{array}{c}\text { Procuradoria do Patrimônio } \\
\text { Imobiliário e Cadastro do } \\
\text { Estado de São Paulo }\end{array}$ & $\begin{array}{c}\text { Instituto de Arqueologia da } \\
\text { Colômbia }\end{array}$ \\
\hline Liceu Francês de Cabul & $\begin{array}{c}\text { Escola Universitária de São } \\
\text { Paulo }\end{array}$ & $\begin{array}{c}\text { Instituto Geológico e } \\
\text { Geográfico }\end{array}$ \\
\hline $\begin{array}{c}\text { Instituto Histórico e Geo- } \\
\text { gráfico de Minas Gerais }\end{array}$ & Colégio Presidente \\
Roosevelt & Instituto de Engenharia \\
\hline
\end{tabular}




\begin{tabular}{|c|c|c|}
\hline $\begin{array}{c}\text { Sociedade de Biologia do } \\
\text { Brasil }\end{array}$ & Universidade de Columbia & Universidade de Barcelona \\
\hline $\begin{array}{c}\text { Instituto Português de } \\
\text { Arqueologia, História e } \\
\text { Etnografia }\end{array}$ & $\begin{array}{c}\text { Instituto Brasileiro de Geo- } \\
\text { grafia e Estatística }\end{array}$ & $\begin{array}{c}\text { Instituto Frances de Arque- } \\
\text { ologia Oriental do Cairo }\end{array}$ \\
\hline Universidade de São Paulo & $\begin{array}{c}\text { Clube de Ciências de } \\
\text { Piracicaba }\end{array}$ & Instituto Butantã \\
\hline $\begin{array}{c}\text { Universidade de Jerusalém } \\
\text { Índio }\end{array}$ & $\begin{array}{c}\text { Serviço de Proteção ao } \\
\text { Auseu Faraônico de Arte } \\
\text { Campos de Arte Copta }\end{array}$ \\
\hline Universidade Upsala & Serviço do Patrimônio His- & $\begin{array}{c}\text { Departamento de Antropo- } \\
\text { logia da Escola de Sociolo- } \\
\text { gia e Política }\end{array}$ \\
\hline
\end{tabular}

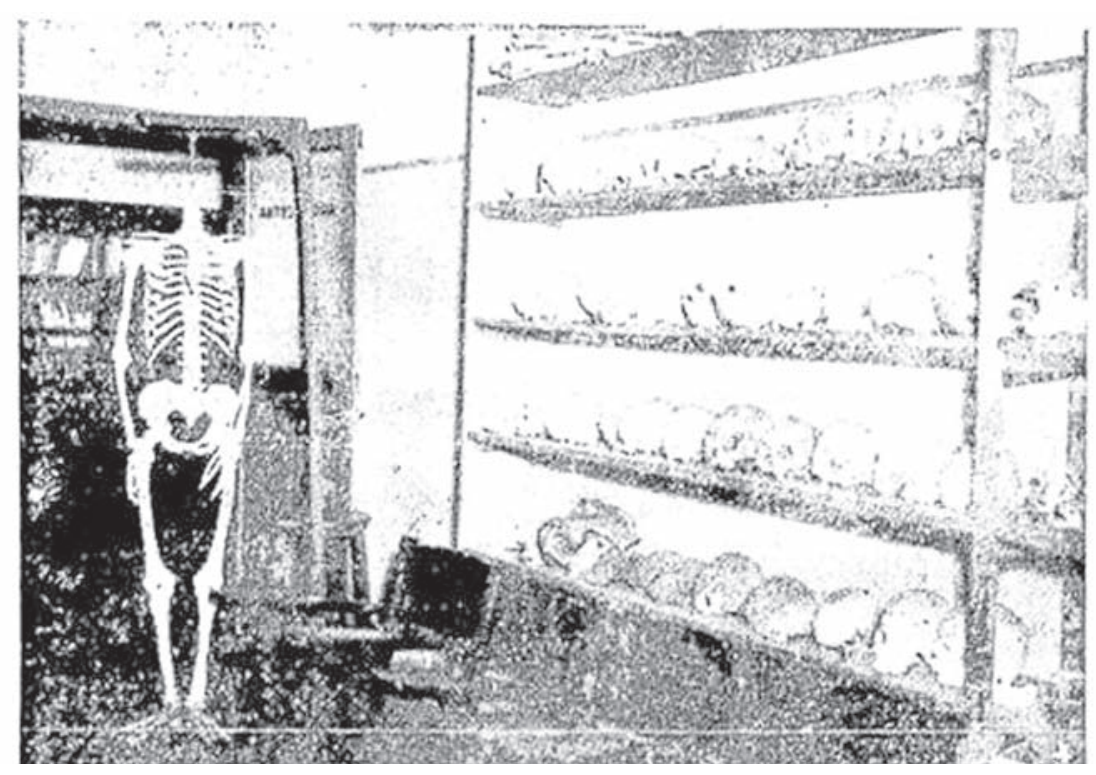

Cranios de fosseis e de indigenas que servem aos estudos da antropologia da Faculdade de Filosofia, Ciencias e Letras

Figura 4. Crânios indígenas na Faculdade de Filosofia, Ciências e Letras. Folha da Manhã, 07/06/1953.

No que concerne aos assuntos, há predomínio da Arqueologia Brasileira, com 26 aparições (sendo 13 sobre Sambaquis, 6 sobre Amazônia e 7 sobre o Brasil em geral), seguida da Arqueologia Clássica (4), Evolucionismo (1), Arqueologia na França (1), Arqueologia no Egito (3), Arqueologia no Afeganistão (1), Arqueologia Bíblica (4), Arqueologia em Portugal (3), 
Arqueologia na Turquia (1), Arqueologia na Áustria (1), Arqueologia nos EUA (1), Arqueologia na Bolívia (1), Arqueologia na China (1), Arqueologia Urbana (sobre a arqueologia do asfalto em Nova York!) (1), Arqueologia Pré-colombiana (3) e Arqueologia no Iraque (1). A "Arqueologia Submarina" ganha uma reportagem especial em setembro de 1948, na Folha da Manhã, e irá destacar-se em São Paulo na próxima década.

\section{Os anos de 1950}

No escopo do período aqui abordado, é na década de 1950 que proliferam notícias que permitem notar a efervescência da Arqueologia na cidade de São Paulo no que concerne a pluralidade de sujeitos e locais de pesquisa e fala, para depois percorrer um longo caminho de obscuridade pós-anos 1960, momento que necessita de um mergulho detalhado a fim de compreender qual a relação, entre a ditadura cívico-militar, a Arqueologia e o fortalecimento de instituições oficiais que ganham, ou tomam para si, o direito de fazer Arqueologia. O período é marcado pelo fortalecimento da profissionalização, acompanhada do crescimento da atuação governamental e das missões estrangeiras em pesquisas com forte abordagem histórico-cultural. ${ }^{43}$ Mais e mais pesquisadores, como será visto, estão ligados a universidade e museus.

Aumenta a quantidade de cursos, palestras e conferências na cidade de São Paulo. Em 1952, dois cursos sobre Arqueologia Bíblica: um no departamento de Letras Orientais da Faculdade de Filosofia da USP e outro pelo arqueólogo Alexandre Rosenfeld da Universidade Hebraica de Jerusalém; no mesmo ano, Loureiro Fernandes é convidado a ministrar um curso de Folclore no Conservatório Dramático e Musical de São Paulo pela Comissão de Folclore e do Centro de Pesquisas Folclóricas Mário de Andrade; em 1957, o Prof. Pinkus, do Centro Bíblico, oferece aulas de Arqueologia e hebraico. Dois cursos são oferecidos sobre Arqueologia Clássica: um de férias, a cargo da Academia Goethiana, na Biblioteca Municipal (1952), e outro pela USP, no âmbito do curso de grego de Robert Henri Aubreton, intitulado "O lugar da Arqueologia no estudo do grego" (1954). José Pereira Júnior, em 1952, ministra o curso "Algumas questões de Arqueologia Brasileira", na Biblioteca Municipal, pelo IHGSP e a Sociedade de Americanistas de Paris, sob os auspícios do Centro Cultural Brasil-Suécia.

Os periódicos publicam chamadas para um curso de Arqueologia com visita a antiga aldeia da Saxônia, só para mulheres, no colégio inglês Denman, em 1950, e para o primeiro curso experimental de Arqueologia Submarina na Itália, no final da década, em 1959. Herbert Baldus, em 1954,

43 POLITIS, Gustavo G. The theoretical landscape and the methodological development of Archaeology in Latin America. Latin American Antiquity, v.14, n.2, p.115-142, 2003. 
convida o arqueólogo norueguês Thor Heyerdhal, após o Congresso de Americanistas, para palestrar sobre arqueologia em Galápagos. Em 1953, a Folha da Manhã anuncia o $9^{\circ}$ Congresso Internacional de Estudos Bizantinos, na Grécia. Em 1954, São Paulo cedia o XXXI Congresso Internacional de Americanistas, com presença de diversos arqueólogos; entre 1958 e 1959, ganham destaque na Folha da Manhã as pesquisas etnoarqueológicas de Loureiro Fernandes sobre os Xetá, uma das primeiras do tipo no âmbito latinoamericano ${ }^{44} \mathrm{com}$ filme apresentado no $1^{\circ}$ Seminário Interamericano de Estudos Municipais na FESPSP.

Em novembro de 1956, o estadounidense Wesley R. Hurt Jr., da Universidade do Paraná, é convidado a proferir palestra na FESPSP sobre a continuidade das pesquisas arqueológicas de Peter Lund em Lagoa Santa. Junto de Hurt vêm para São Paulo Fernando Altenfelder, um ex-aluno de Baldus, e Oldemar Blasis, da mesma universidade. O casal Betty Meggers e Clifford Evans aparecem como os arqueólogos americanos mais influentes no país; suas pesquisas em Lagoa Santa rendem as primeiras datações radiocarbônicas de níveis arqueológicos; Hurt participa da fundação do Museu Paranaense, novo centro de estudos arqueológicos, divulgado em notícias pelo jornal Folha da Manhã ao longo de 1958.

Em 1957, no Hospital das Clínicas, Manuel O. Zariquiey conferencia sobre a aplicação do raio-X na Arqueologia. De 1957 a 1959, a Arqueologia Submarina ganha destaque nos meios de comunicação: João Paiva Carvalho, professor do Departamento Oceanográfico, junto da Escola de Educação Física e da Escola de Mergulho Nautillus, ministra aulas em São Paulo, em uma das primeiras iniciativas no campo subaquático.

Neste momento emerge a figura de José Anthero Pereira Jr., sem dúvida, um dos pioneiros da Arqueologia Paulista. No começo da década, Pereira Jr. publica trabalhos associados à cerâmica tupi-guarani escavada em Franca e Guaíra, interior do estado. Em 1959, recebe de Paulo Duarte, para análise, cerâmicas indígenas localizadas por movimentação de terra no bairro do Morumbi. ${ }^{45}$

O papel político de Paulo Duarte, à frente do IPH, ganha força. Um caso divulgado nos jornais é bastante ilustrativo: a acusação de furto de uma urna marajoara, vinda de Belém para o Museu Paulista, pelo ex-governador do estado, Adhemar de Barros. O episódio, ocorrido em 1956 e divulgado pelo Diário Oficial, envolveu como testemunhas não só Paulo Duarte, que acusava Adhemar e pedia seu afastamento da vida política, como Sérgio Buarque de Holanda, então diretor do Museu Paulista, e Herbert Baldus. Os dois últimos chegaram a localizar outra urna, que não a desaparecida,

44 POLITIS, Gustavo G. Acerca de la Etnoarqueología en América del Sur. Horizontes Antropológicos, v.18, n.18, p.61-91, 2002.

45 PEREIRA JR., José A. Cerâmica indígena do bairro do Morumbi (primeiras informações). 
na casa do ex-governador, e requisitaram sua doação ao Museu. O caso é evidente do uso da Arqueologia para forçar Adhemar de Barros a abandonar a carreira política, como fica claro no depoimento de Paulo Duarte sobre o caso.

A luta pela proteção dos sambaquis continua, acompanhada da divulgação de seu potencial. São inúmeros os que se envolvem com a questão, de diversas instituições. Em julho de 1950, Arimondi Falconi, do Instituto Paulista de Oceanografia, profere fala sobre a proteção dos sambaquis em Santos. No final de 1950, com base no decreto de 1947, é designado o pessoal para constituir a Comissão Permanente de Estudo e Proteção dos Sambaquis do Estado de São Paulo: José Bueno de Oliveira Azevedo Filho (do diretório regional de Geografia do Estado), Sergio Mezzalira (do Instituto Geológico e Geográfico), Plínio Ayrosa (Faculdade de Filosofia), Frederico Lane (Museu Paulista), Oliverio Mario de Oliveira Pinto (Departamento de Zoologia) e Raul Cintra Leite (Procurador do Patrimônio Imobiliário). Em meados de 1951, Otorini di Fiori, professor da Faculdade de Medicina, é afastado da Comissão para uma longa estadia na Europa.

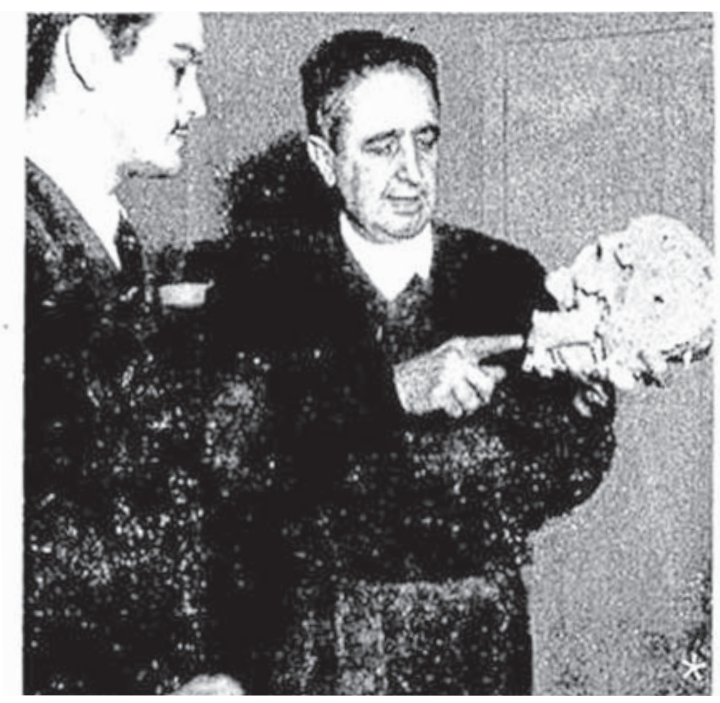

O sr. Paulo Duarte apresenta "miss-sambaqui", um cranio feminino encontrado num sambaqui de Cubatão e que tem mais de 7.000 anos

Figura 5. Paulo Duarte apresenta a "miss-sambaqui". Folha da Manhã, 20/03/1959.

Em 1952, o Decreto Estadual 21.935 estipula a criação da chamada Comissão de Pré-História, composta por Paulo Duarte, Frei Reginaldo de Sá, Egon Schaden (Faculdade de Filosofia, Ciências e Letras), Herbert Baldus 
(Museu Paulista), Waldemar Lefevre (Instituto Geológico e Geográfico) e Manoel Joaquim de Albuquerque Lins Netto (assessoria técnico-legislativa). Por todo o ano de 1953, a Comissão, através do Diário Oficial de São Paulo, convida os concessionários de exploração de sambaquis do Estado para discussão do decreto a fim de proceder ao tombamento das "jazidas". Durante toda a década de 1950, publica artigos nos principais periódicos sobre a destruição dos sambaquis do litoral, apresentando dados também sobre o vale do Ribeira. Fruto da conhecida luta política de Paulo Duarte para a preservação dos sambaquis, a Comissão tornou-se o núcleo do futuro Instituto de Pré-História, ${ }^{46}$ criado em 1952, vinculado à Casa Civil da Presidência da República e incorporado à USP em 1963.

Em 1954, Pereira Jr. aparece como membro da Comissão de PréHistória; no mesmo ano, o casal Lotte e Artur Sievers, da Sociedade de Americanistas de Paris, a convite de Baldus, visitam São Paulo atraídos por sua "paixão" pelos sambaquis. Este é o ano também das escavações do sambaqui Maratuá (Bertioga) pelos Emperaire, Paulo Duarte e Paul Rivet, já pelo IPH (da missão arqueológica participou também José Pereira Jr.). Parece ser proveniente dele o crânio da "Miss-Sambaqui" apresentado a Folha da Manhã por Paulo Duarte; dois anos antes, Duarte e Rivet escavaram sambaqui em Cananéia. De abril a setembro de 1954 e de maio de 1955 a abril de 1956, a missão franco-brasiliana realizou duas campanhas, entre a região lagunar de lguape (SP) e Araripina (PR), trabalhando nos sambaquis paulistas de Boa Vista (Ilha Comprida), Boguassu, Aroeras, das Ostras, Reyes I, Reyes II, Andradas, Nobrega, da Brucuanha, Matinhos, Subauna e do Itingussú (todos em Cananéia). ${ }^{47}$

As chamadas missions archaéologiques tiveram papel fundamental na formação de toda uma nova geração de arqueólogos brasileiros, em especial quanto a um rigor metodológico. O casal Emperaire, trazido a convite de Paul Rivet (convidado por Paulo Duarte), insere-se nas 17 missões arqueológicas francesas que ocorreram por toda a América Latina, no âmbito do "americanismo" crescente, desde o final do século XIX, com a fundação da Sociedade de Americanistas, ligada ao Museu do Homem de Paris. O interesse das missões estava também em investigar culturas menos conhecidas que as maia, inca e asteca. ${ }^{48}$ Em maio de 1954, por exemplo, a Folha da Manhã relata as pesquisas de Henri Lehmann, do Museu do Homem de Paris, na Guatemala.

Entre o final de 1957 e 1958, comemora-se o tombamento dos sambaquis paulistas e a criação de reservas florestais, já no governo Juscelino

46 BARRETO, Cristina. A construção de um passado pré-colonial.

47 EMPERAIRE, Joseph; LAMING, Anette. Les sambaquis de la cote méridional du Brésil (Campagnes de fouilles (1954-1956)). Journal de la Société des Américanistes, v.45, n.1, p.5-16, 1956.

48 BARRETO, Cristina. A construção de um passado pré-colonial. 
Kubistchek, como a da Ilha do Cardoso, que permitiriam a proteção de inúmeros sítios do tipo. Em 1958, pela Folha da Manhã, chegam as notícias sobre o desenvolvimento da Arqueologia paranaense, realizada pelo Centro de Estudos e Pesquisas Arqueológicas (CEPA), encabeçado por Loureiro Fernandes, o Museu de Artes Populares de Paranaguá e a Universidade do Paraná, nos sambaquis de Corisco, Antonina e Guaraguaçu, onde Margarida Andreatta, deve-se lembrar, realiza seus primeiros estágios em campo; destas escavações participa também Waldemar Lefevre. Em 1958, Ulpiano Meneses, que nos anos 1960 estaria à frente da criação do Museu de Arte e Arqueologia, dá início a sua graduação em Letras na Universidade de São Paulo.

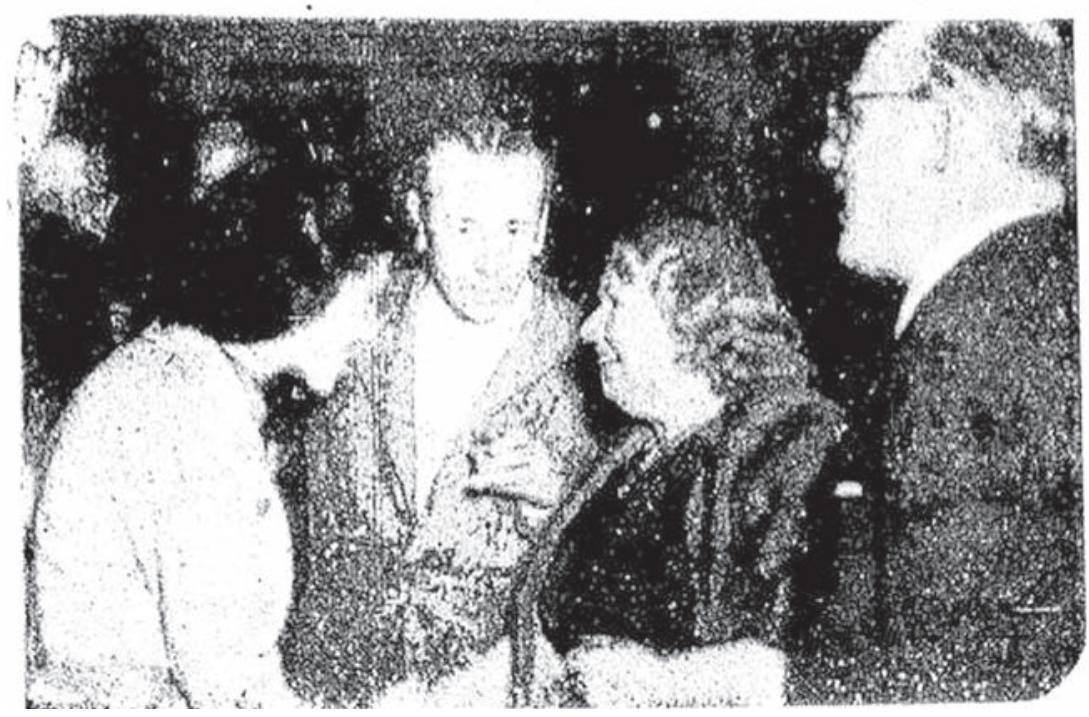

Herbert Baldus apresenta os congressistas aos anfitriões

Figura 6. Herbet Baldus e o casal Sievers. Folha da Manhã, 29/08/1954

Fortalece-se a vinda de inúmeros franceses. Durante toda a década, publicam-se reportagens sobre André Malraux, arqueólogo e político militante, Ministro de Informações da França. O destaque a suas pesquisas arqueológicas na China e Indonésia é dado também quando, em 1959, vem a São Paulo proferir palestra na Faculdade de Filosofia da USP.

Vale lembrar aqui duas instituições fundadas no período: a primeira delas, que sofrerá duros golpes com os anos 1960, é a ABEPA, a Associação Brasileira de Estudos e Pesquisas Arqueológicas. Inaugurada em maio de 1958 por comerciantes, tipógrafos, professores, advogados, repórteres e industriais, arqueólogos "amadores", contando com 300 sócios em 1959, teve 
como patrono Bernardo Azevedo da Silva Ramos, que realizou pesquisas na Pedra da Gávea e chegou a doar peças arqueológicas para o Museu de Arte Moderna. Com sede no Rio de Janeiro, a ABEPA financiou uma grande exposição, a la Exposição Internacional de Arqueologia no Brasil, anunciada inúmeras vezes pela Folha da Manhã e pela Folha da Noite, sob a organização de Roldão Pires Brandão. Além dessa, os jornais anunciariam, para esta década, apenas mais uma exposição, de Arqueologia Pré-colombiana, organizada pelos arqueólogos peruanos Pedro e Maria Velasco, ocorrida no Instituto dos Arquitetos do Brasil em São Paulo, em 1954.

Em 1959, Paulo Duarte torna-se diretor do Museu Paulista, propondo reformulações em seu quadro. Anteriormente, em 1953, Herbet Baldus havia lançado a ideia de um Museu do Índio Brasileiro em São Paulo, tendo em vista as comemorações do IV Centenário. Em 1959, Paulo Duarte consolida a ideia de um Museu do Homem Americano a ser instalado no Palácio da Agricultura, no Parque do Ibirapuera, também durante o IV Centenário. Entretanto, a proposta que se realiza é a da entrada do IPH para a USP, mais tarde, em 1963. ${ }^{49}$

No que concerne aos periódicos investigados, há novamente um predomínio de reportagens sobre Arqueologia Brasileira, sendo 36 sobre Sambaquis, 17 sobre Arqueologia Amazônica, 11 sobre Arqueologia Brasileira em geral. São seguidos pela Arqueologia Clássica (16), Pré-Colombiana (12), Egito (13), Bíblica (11), Submarina (8), Índia (5), Iraque (5), EUA (4), datação (3), Viking (3) Jerusalém (3), sobre raios-X aplicado à Arqueologia (2), Nairóbi (2), Indochina (2), França (2), Afeganistão, África, Argélia, Bulgária, Canadá, China, Indonésia, Creta, Arqueologia e restauração, Fenícios, Arqueologia Gótica, Inglaterra, Irã, Israel, Knossos, Malásia, Mar Morto, Marrocos, Nigéria, Oriente Médio, Portugal, Síria, Tunísia, Venezuela, sobre conservação de metais arqueológicos, sobre megafauna e sobre ofertas de bolsas de estudos em arqueologia na Suécia, junto a CAPES e a Fundação Eli Wagner de Estocolmo (uma de cada).

Ao público leitor, corre um sem número de atores envolvidos com a Arqueologia, em diversas partes do mundo: 107 pessoas são citadas, 50\% a mais do que na década anterior. Deste total, há onze mulheres. O final dos anos 1940 e certamente os anos 1950 (culminando com o feminismo nas décadas posteriores) marca a luta política feminina que resultará na formação das primeiras arqueólogas. "Ausentes ou subjugadas, emergiram como sujeitos sociais cada vez mais ativos". ${ }^{50}$ Kathleen Kenyon, por exemplo, fora pioneira e inspirou muitos a partir dos anos de 1940. Suas pesquisas em Jericó pelo Escritório Britânico de Arqueologia de Jerusalém

49 WICHERS, Camila A. M. Patrimônio Arqueológico Paulista.

50 FERREIRA, Lúcio M.; FUNARI, Pedro P. A. Arqueologia como prática política. Boletim do Museu Paraense Emilio Goeldi-Ciências Humanas, v.4, n.1, p.71-91, 2009. 
são divulgadas pela Folha da Manhã de 15/04/1955. O mesmo periódico, em seu Suplemento Feminino, destacava a atuação de mulheres de sucesso, como as arqueólogas Julienne Moulinasse (1956) e Claire Praux (1958) em suas pesquisas na França, Grécia, África e Oriente Médio. No final dos anos de 1950, as futuras arqueólogas Niede Guidon (Universidade de São Paulo), Luciana Pallestrini (Universidade de São Paulo), Silvia Maranca (Pontifícia Universidade Católica de São Paulo) e Ruth Kunzli (Faculdade de Filosofia Ciências e Letras de Presidente Prudente) dão início a suas graduações em São Paulo (com exceção de Kunzli, no interior).

Em novembro de 1959, a Folha da Manhã publica matéria de capa na qual a equipe, exclusivamente feminina, da Seção de Etnologia do Museu Paulista é chamada a escavar, em Guarulhos, devido às obras da Dutra, uma aldeia guarani de 200 a 400 anos de idade. Formavam o grupo: Vilma Chiari, Lia de Freitas, Luciana Pallestrini e Niede Guidon. Suas pesquisas já adotavam perspectivas processualistas, como estudos de variabilidade morfológica, distribuição espacial e padrões de assentamento, dialógicas a um movimento de inovações teóricas que ultrapassava a ortodoxia históricocultural, não apenas no Brasil, mas no continente americano como um todo, a partir dos anos de 1950 e $1960 .^{51}$

\section{Quadro 5}

Pesquisadores citados nos periódicos nos anos 1950

\begin{tabular}{|c|c|c|}
\hline Alexandre Rosenfeld & Claire Praux & Henry B. Collins \\
\hline Alfonso Caso & Claude Schaeffer & Herbert Baldus \\
\hline André Malraux & André Perrot & Sérgio Buarque \\
\hline Angyone Costa & Diocleciano R. de Campos & Paulo Duarte \\
\hline Anil da Silva & Egon Shaden & I. W. I. Bullok \\
\hline Antonio Segni & Ezio Cannata & Jean Rackim \\
\hline Arimondi Falconi & $\begin{array}{l}\text { Margarida Guarducci } \\
\text { Cannata }\end{array}$ & $\begin{array}{c}\text { José Bueno de Oliveira } \\
\text { Azevedo Filho }\end{array}$ \\
\hline Aristides Pileggi & Ferdinando Castagnoli & Sergio Mezzalira \\
\hline Gastão Cruls & Lucas Cozza & Frederico Lane \\
\hline Dorothy Garrod & Fransico Braga Hardi & Plínio Airosa \\
\hline Robert Braidwood & Fred Wendorf & $\begin{array}{c}\text { Oliverio Mario de Oliveira } \\
\text { Pinto }\end{array}$ \\
\hline Ralph Solecki & Frederico Barata & Raul Cintra Leite \\
\hline Pedro e Maria Velasco & Frei Reginaldo Sá & José Pereira Jr. \\
\hline Arthur Evans & General Igal Yadin & Joseph M. Cruxent \\
\hline
\end{tabular}

51 TRIGGER, Bruce. Historia do pensamento arqueológico. São Paulo: Odysseus, 2004 


\begin{tabular}{|c|c|c|}
\hline Betty Meggers & George E. Mylonas & Julienne Moulinasse \\
\hline Clifford Evans & George Hanfam & Kathleen Keynos \\
\hline Bobb Schaeffer & George Michenowsky & Ladislau Neto \\
\hline Brian Fawcett & Gordon Childe & Lady Wheeler \\
\hline C. H. Gordon & Hallam L. Movius Jr. & Prof. Leakov \\
\hline C. W. Ceram & Henri Lehmann & Lotte e Artur Sievers \\
\hline Luis Altenfelder & Mac Leish & Manuel O. Zariquiey \\
\hline Marcel F. Hamet & Mortimer Wheeler & Naji-al-Asil \\
\hline Arche Dogy & Otorino de Fiori & Paul Rivet \\
\hline Waldemar Lefevre & José Pereira Jr & Frei Reginaldo de Sá \\
\hline $\begin{array}{l}\text { Manoel Joaquim de Albu- } \\
\text { querque Lins Netto }\end{array}$ & Paulo Schluz & Peter Williams-Hunt \\
\hline Philippe Dolé & Piero Nicola Gargallo & Prof. Jeffreys \\
\hline João Paiva Carvalho & José Camargo Mendes & Prof. Pinkus \\
\hline Silveira Bueno & Raymond Pons & Dr. Drioton \\
\hline Charles Uentz & rei Farouk I & Ricardo Krone \\
\hline Robert Henri Aubreton & Robert Verones & Roldão Pires Brandão \\
\hline Prof. Shliemann & Thor Heyerdhal & Tomás Benthel \\
\hline Tullia Picelli & Valter Zanini & Max Parrish \\
\hline Wandell C. Bennet & Wesley Hurt & Fernando Altenfelder \\
\hline Oldemar Blasis & Wilham B. Dinsmoore & Zakaria Ghoneim \\
\hline Luciana Pallestrini & Silvia Maranca & Lia de Freitas \\
\hline Vilma Chiari & Loureiro Fernandes & \\
\hline
\end{tabular}

Estes atores provinham de diversas instituições, sendo que 34 tinham sede em São Paulo! Vale destacar a chamada "Operação Caiçara", criada em 1958, com objetivo de realizar estudos para o desenvolvimento socioeconômico e ordenamento territorial do vale do Ribeira. Fora uma das primeiras experiências de política de planejamento, realizada no governo Carvalho Pinto (1959-1963), enquanto parte da Comissão do Litoral do Estado, sob presidência da Secretaria do Trabalho, Indústria e Comércio. ${ }^{52} \mathrm{O}$ Diário Oficial de São Paulo de 05/11/1959 divulgou as pesquisas da "Nova Operação Caiçara", agora na região sudeste de São Paulo, prevendo uma comissão técnica que estudaria as condições de vida dos índios e das zonas onde estão localizados sambaquis (Itanhaém, Suarão, Tainguá e Iperoíbe).

52 RESENDE, Roberto U. As regras do jogo. São Paulo: Annablume, Fapesp, 2002; TODESCO, Carolina. Estado e terceiro setor na organização do espaço para o turismo no vale do Ribeira. São Paulo: Universidade de São Paulo, 2007 (Geografia Humana, Tese de doutorado). 


\section{Quadro 6}

Instituições citadas nos periódicos nos anos 1950

\begin{tabular}{|c|c|c|}
\hline $\begin{array}{c}\text { Associação Brasileira } \\
\text { de Pesquisas e Estudos } \\
\text { Arqueológicos }\end{array}$ & $\begin{array}{c}\text { Conselho de Arqueologia } \\
\text { Britânica }\end{array}$ & Secretaria Médica \\
\hline $\begin{array}{l}\text { Academia Francesa de } \\
\text { Inscripção }\end{array}$ & Departamento de Cultura & Fotocine Clube Bandeirante \\
\hline $\begin{array}{c}\text { Academia Polonesa de } \\
\text { Ciências }\end{array}$ & $\begin{array}{c}\text { Departamento de } \\
\text { Paleontologia/FF/USP }\end{array}$ & $\begin{array}{c}\text { Instituto Frances de Arque- } \\
\text { ologia Oriental }\end{array}$ \\
\hline Biblioteca Municipal & $\begin{array}{l}\text { Departamento Egípcio de } \\
\text { Antiguidades }\end{array}$ & $\begin{array}{l}\text { Museu do Homem Ameri- } \\
\text { cano em São Paulo }\end{array}$ \\
\hline Academia Goethiana & $\begin{array}{l}\text { Departamento } \\
\text { Oceanográfico }\end{array}$ & $\begin{array}{c}\text { Instituto de Pré-História e } \\
\text { Etnografia }\end{array}$ \\
\hline IHGSP & Escola de Educação Física & $\begin{array}{l}\text { Museu Paraense Emílio } \\
\text { Goeldi }\end{array}$ \\
\hline $\begin{array}{c}\text { Sociedade de Americanis- } \\
\text { tas de Paris }\end{array}$ & $\begin{array}{c}\text { Escola de Mergulho } \\
\text { Nautillus }\end{array}$ & Museu Nacional do Canadá \\
\hline $\begin{array}{l}\text { Centro Cultural } \\
\text { Brasil-Suécia }\end{array}$ & $\begin{array}{l}\text { Divisão de Caça e Pesca } \\
\text { da Secretaria de Agricultura }\end{array}$ & Museu Paulista \\
\hline Capes & DPHAN & $\begin{array}{c}\text { Museu Sudoeste de Los } \\
\text { Angeles (EUA }\end{array}$ \\
\hline Fundação Eli Wagner & $\begin{array}{c}\text { Escola de Sociologia e } \\
\text { Política }\end{array}$ & Operação Caiçara \\
\hline Centro Bíblico & $\begin{array}{l}\text { Escritório Britânico de Ar- } \\
\text { queologia de Jerusalém }\end{array}$ & $\begin{array}{c}\text { Pontifícia Academia Roma- } \\
\text { na de Arqueologia }\end{array}$ \\
\hline $\begin{array}{l}\text { Centro de Estudos e Pes- } \\
\text { quisas Arqueológica }\end{array}$ & Faculdade Medicina & Universidade de Yale \\
\hline $\begin{array}{l}\text { Colégio Denman } \\
\text { (Inglaterra) }\end{array}$ & $\begin{array}{c}\text { Faculdade de Arquitetura/ } \\
\text { USP }\end{array}$ & $\begin{array}{c}\text { Seção Regional de São } \\
\text { Paulo da Sociedade Botâni- } \\
\text { ca do Brasil }\end{array}$ \\
\hline $\begin{array}{c}\text { Comissão da Secretaria da } \\
\text { Agricultura }\end{array}$ & Faculdade de Filosofia/USP & $\begin{array}{l}\text { Serviço de Patrimônio His- } \\
\text { tórico e Artísitico Municipal }\end{array}$ \\
\hline $\begin{array}{c}\text { Comissão de Geographia e } \\
\text { Geologia }\end{array}$ & Fundação Amazônica & Smithsonian Institute \\
\hline Comissão de Pré-História & Hospital das Clínicas & $\begin{array}{c}\text { Sociedade de Americanis- } \\
\text { tas de Paris }\end{array}$ \\
\hline $\begin{array}{l}\text { Comissão Permanente de } \\
\text { Estudo e Proteção dos } \\
\text { Sambaquis do Estado de } \\
\text { São Paulo }\end{array}$ & $\begin{array}{c}\text { Internacional de Easteman } \\
\text { Kodak (EUA) }\end{array}$ & $\begin{array}{c}\text { Sociedade Palestinense } \\
\text { Russa }\end{array}$ \\
\hline $\begin{array}{c}\text { Instituto Paulista de } \\
\text { Oceanografia }\end{array}$ & $\begin{array}{c}\text { Museu de Arqueologia de } \\
\text { Paranaguá }\end{array}$ & Universidade de Chicago \\
\hline $\begin{array}{l}\text { Conselho Americano de } \\
\text { Associações Culturais }\end{array}$ & $\begin{array}{l}\text { Museu de Arqueologia e } \\
\text { Artes Populares do Paraná }\end{array}$ & $\begin{array}{l}\text { Universidade da } \\
\text { Pensilvânia }\end{array}$ \\
\hline
\end{tabular}




\begin{tabular}{|c|c|c|}
\hline $\begin{array}{c}\text { Instituto Científico Judaico } \\
\text { da Academia Búlgara de } \\
\text { Ciências }\end{array}$ & $\begin{array}{l}\text { Museu de Arte de São } \\
\text { Paulo }\end{array}$ & Universidade de Bruxelas \\
\hline $\begin{array}{c}\text { Instituto de Arqueologia de } \\
\text { Paris }\end{array}$ & $\begin{array}{l}\text { Museu de Arte e Arqueolo- } \\
\text { gia de Mariemont (Bélgica) }\end{array}$ & Universidade de Harvard \\
\hline $\begin{array}{l}\text { Instituto de Arqueologia } \\
\text { Submarina em Roma }\end{array}$ & Museu de Bardo (Argélia) & $\begin{array}{c}\text { Museu de Arqueologia de } \\
\text { N. S. Aparecida }\end{array}$ \\
\hline Museu de Brooklyn (EUA), & $\begin{array}{c}\text { Museu de Ciências } \\
\text { Naturais de Caracas } \\
\text { (Venezuela), }\end{array}$ & $\begin{array}{c}\text { Museu de Antropologia e } \\
\text { Arqueologia da Universida- } \\
\text { de de Cambridge }\end{array}$ \\
\hline Universidade de Michigan & Universidade de Londres & Museu do Homem de Paris \\
\hline $\begin{array}{l}\text { Instituto dos Arquitetos de } \\
\text { São Paulo }\end{array}$ & Universidade do Paraná & Missão Franco-Brasileira \\
\hline $\begin{array}{l}\text { Instituto Frances de Arque- } \\
\text { ologia Oriental }\end{array}$ & $\begin{array}{c}\text { Universidade Hebraica de } \\
\text { Jerusalém }\end{array}$ & Ministério da Agricultura \\
\hline $\begin{array}{c}\text { Serviço de Antiguidade do } \\
\text { Egito }\end{array}$ & Universidade de Harvard & Museu de Arte Moderna \\
\hline $\begin{array}{c}\text { Instituto de Arqueologia da } \\
\text { Universidade de Munique } \\
\text { (Dinamarca) }\end{array}$ & $\begin{array}{l}\text { Universidade de } \\
\text { Washington }\end{array}$ & Liceu Condorcet (França) \\
\hline $\begin{array}{l}\text { Laboratório de Antropolo- } \\
\text { gia do Novo México (EUA) }\end{array}$ & 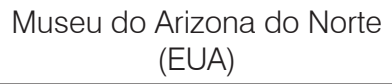 & \\
\hline
\end{tabular}

Importa ressaltar, por fim, a emergência, nos anos 1950, de figura que gradativamente aproximar-se-ia da Arqueologia, o ceramógrafo Eldino Fonseca Brancante, advogado, membro do IHGSP, do Instituto Genealógico Latino, da Academia Paulista de Letras, sócio do Jockey Club, amigo de Guilherme de Almeida, jornalista envolvido nas obras de restauro da Casa do Bandeirante, em 1954, com Luís Saia. Brancante fora companheiro, como heraldista do Instituto Genealógico Brasileiro, de Enzo da Silveira, redator-chefe da seção de esportes do jornal Correio de S. Paulo, microbiologista e autor de livros de Arqueologia. Brancante, com os anos 1940 e 1950, envolve-se nas pesquisas sobre louçaria em São Paulo, compondo diversas exposições, catálogos e coleções de museus.

Em 1950, lança "O Brasil e a Louça da Índia" e, em 1954, "A cerâmica na Vila de São Paulo", obras de referência para os primeiros pesquisadores de Arqueologia Histórica. Com os anos 1980, Brancante orienta alguns arqueólogos (como Paulo Zanettini, aluno de Margarida Andreatta) na questão das análises de materiais (em especial, as louças, cunhando termos como "faiança fina") e escava e analisa um sítio arqueológico em São Sebastião, produzindo sobre isso o manuscrito inédito "O Buraco do Bicho", em 1993. 


\section{Considerações finais}

A produção do saber e de um discurso científico autorizado por uma instituição que detém certo poder caracteriza o processo de formação de inúmeros campos, dentre eles, certamente, a Arqueologia no Brasil. O postulado da "verdade científica" orquestrou a Arqueologia como campo social no qual relações de força, monopólio, lutas, estratégias, interesses e lugares conformaram a ciência em São Paulo. No período estudado, ficam claros seus aspectos enquanto luta concorrencial, como define Pierre Bourdieu, ${ }^{53}$ uma vez que a partir dos anos de 1950, e certamente com os anos de 1960, assiste-se a imbróglios pelo monopólio da autoridade científica (a capacidade técnica e o poder social) e pela competência científica (falar e agir legitimamente autorizado e com autoridade), veementemente, na Arqueologia.

A outorga social do discurso científico, enquanto uma verdade que prevalece, está, em São Paulo, associada à institucionalização cada vez maior da Arqueologia nas universidades e museus e na luta de alguns por seu reconhecimento junto às "ciências". Alguns intelectuais passam a formar, assim, uma única comunidade epistêmica, ${ }^{54}$ construída por rede de profissionais com reconhecida perícia, autoridade e competência em assuntos específicos, em detrimento de toda uma pluralidade de locais e vozes que pensavam a Arqueologia em São Paulo. Aqueles que permaneceram de fora destas comunidades, legitimadas por seus próprios discursos científicos e pelo Estado, ou em instituições com menor poder político, passaram a ser tachados, negativamente, de "amadores". Uma das vítimas deste processo de profissionalização foi, sem dúvida, Guilherme Tiburtius, acusado de destruir sítios arqueológicos e obrigado a abandonar suas atividades. ${ }^{55}$ Realizou escavações em Santa Catarina e no Paraná, algumas das quais com José Bigarella pela Universidade Federal do Paraná; sua coleção, famosa pelos zoólitos, deu origem ao Museu do Sambaqui de Joiville (SC), em 1963.

Isto pareceu ocorrer independente da formação acadêmica de muitos (já que inexistia uma formação específica em Arqueologia) ou de suas interpretações (fenícios, vikings, Atlântida etc.), associando-se à própria instituição ou grupo de intelectuais a que se relacionavam. De modo geral, um processo de silenciamento da pluralidade da Arqueologia deu-se, com o fim dos anos 1950 e, particularmente, com o golpe de 1964, a partir de instituições do Estado (como as universidades e institutos públicos), às quais se vincularam determinados intelectuais, em especial aqueles cuja

53 BOURDIEU, Pierre. O campo científico. In: ORTIZ, Renato (org.). Bourdieu - Sociologia. São Paulo: Ática. 1983, p.122-155 (Coleção Grandes Cientistas Sociais, v.39).

54 HASS, Peter. Introduction: Epistemic Communities and International Policy Coordination. International Organization V.46, n.1, p.1-35, 1992

55 PROUS, André. Arqueologia Brasileira. 
temática poderia ser utilizada para fortalecer um discurso de nação moderna a partir da ideia de evolução, progresso e de uma antítese cultural ("o índio"), concomitante a um total desinteresse por temas relacionados à Arqueologia Histórica.

Entre os anos de 1930 e de 1950, através dos periódicos, é possível acompanhar o efervescer e o arrefecer da Arqueologia na região da grande São Paulo e perceber que, no campo, os discursos prevalecentes foram aqueles dominados e confiscados por alguns indivíduos e instituições que se arrogaram o controle exclusivo sobre eles. ${ }^{56}$ Isto acarretou, certamente, uma queda brusca no número de interessados e participantes nas reflexões arqueológicas na região, assim como dos centros e instituições que produziram algum conhecimento sobre a área. Nas décadas pesquisadas, o número de matérias sobre Arqueologia Brasileira sempre suplantou aquelas com temáticas internacionais. O que ocorreu a partir dos anos seguintes? Sakai, Pereira Jr., Tibiriçá, Pereira de Godoy e outros foram alocados no "tempo dos amadores". A Sociedade Brasileira de Arqueólogos Amadores, a Associação Brasileira de Estudos e Pesquisas Arqueológicas e a própria Escola Paulista de Sociologia e Política foram alguns dos centros que enfraqueceram ou mesmo deixaram a Arqueologia a partir dos anos 1960, quando a lei de 1961 finalmente protegeu os sítios arqueológicos e o Museu de Arte e Arqueologia, futuro Museu de Arqueologia e Etnologia, da Universidade de São Paulo fora criado, assim como diversas outras instituições públicas. Daqui em diante, nova etapa pouco explorada teve início: a arqueologia durante o regime militar. Mas isto são outros quinhentos.

56 FOUCAULT, Michel. A ordem do Discurso. São Paulo: Loyola, 1996; CHARTIER, Roger. O mundo como representação. Estudos Avançados, São Paulo, v.5, n.11, p.173-191, 1991. 